\title{
El principio de equilibrio presupuestal como límite constitucional en la negociación colectiva
}

\author{
Mg. Jenny Diaz Grados \\ ddiazgr7@ucvvirtual.edu.pe \\ Universidad César Vallejo \\ Perú
}

\section{RESUMEN}

En la presente investigación se analizará la naturaleza jurídica, del principio de equilibrio presupuestal y su determinación en la estructuración, planificación y ejecución en el presupuesto de las entidades del Estado, presentándolo como una base conceptual, legal y una herramienta de gestión de observancia obligatoria para la ejecución de los procesos de negociación colectiva.

Palabras clave: principio de equilibrio; presupuesto; limite constitucional y negociación colectiva. 


\title{
The principle of budgetary balance as a constitutional limit in collective bargaining
}

\begin{abstract}
This research will analyze the legal nature of the principle of budget balance and its determination in the structuring, planning and execution of the budget of State entities, presenting it as a conceptual and legal basis and a management tool of mandatory observance for the execution of collective bargaining processes.
\end{abstract}

Keywords: principle of balance; budget; constitutional limit and collective bargaining

Artículo recibido: 30 noviembre. 2021 Aceptado para publicación: 29 diciembre 2021 Correspondencia: ddiazgr7@ucvvirtual.edu.pe Conflictos de Interés: Ninguna que declarar 


\section{INTRODUCCIÓN}

Se entiende por derechos fundamentales los atributos de toda persona inherentes a su dignidad, que el estado debe garantizar, respetar y satisfacer. En su aspecto positivo son los que otorga la constitución política de nuestro país y los que se recogen en los pactos, convenios y tratados internacionales suscritos y ratificados por el país. En nuestro ordenamiento constitucional consideramos que por derechos fundamentales o humanos puede entenderse el conjunto de facultades e instituciones que, concretan las exigencias de la libertad, la igualdad y la seguridad humana en cuanto expresión de la dignidad de los seres humanos, en un contexto histórico determinado, las cuales deben ser aseguradas, promovidas y garantizadas por los ordenamientos jurídicos a nivel nacional. En este sentido, la orientación se ha dirigido a defender que el trabajo humano no puede ser confundido con una simple mercancía y que la dignidad del trabajador es un bien jurídico que debe de defenderse y preservarse. La igualdad en el trabajo o igualdad laboral debe entenderse como la práctica de las mismas condiciones de trabajo para hombres y mujeres, sin importar el sexo, el estado civil, su origen étnico o raza, la clase social, la religión o su ideología política.

En este sentido, el derecho al trabajo tiene dentro de su dimensión al derecho constitucional de la negociación colectiva consagrado en el artículo 28 de la Constitución Política del Estado que en su parte pertinente, establece "El Estado reconoce (a los trabajadores en general) los derechos de sindicación, negociación colectiva y huelga"; derecho que según el TC “deberá efectuarse considerando el límite constitucional que impone un presupuesto equilibrado y equitativo, cuya aprobación corresponde al Congreso de la República".

Sin embargo, pese a la trascendencia del equilibrio presupuestal regido en los alcances en la Ley 28411 como componente básico para la negociación colectiva, tanto los sindicatos como algunos representantes de la comisión paritaria poco les importa a la hora de reclamar beneficios laborales de contenido presupuestario así como a la hora de tomar acuerdos, generándose posteriormente la imposibilidad de cumplir con los acuerdos derivados de la negociación colectiva por restricciones presupuestales. Bajo este contexto se promueven de manera desmedida procesos jurisdiccionales y arbitrales a efectos de que se ejecuten los acuerdos tomados. 
El presente artículo describirá en un enfoque cualitativo la trascendencia del equilibrio presupuestal como condición siquanon para la ejecución de los procesos de negociación colectiva y dentro de un enfoque cuantitativo describirá estadísticas relacionadas a la inejecución de laudos arbitrales sobre la materia, complementados con la posición asumida por el TC respecto de este problema.

\section{ANALISIS}

\section{Naturaleza Jurídica del Presupuesto Público}

Todas las estructuras de poder se basan o se sedimentan bajo un parámetro económico que les permita subsistir. Así ha sido desde los imperios. Pese a que la idea de la republica implico romper los esquemas monárquicos, ha habido algo común entre ambos: la necesidad de un presupuesto para existir y para poder cumplir sus fines.

Sobre el particular el autor Jones; precisa que "el principal interés económico del Estado en la Antigüedad era el cobro de impuestos para poder satisfacer los gastos militares. Para lograr este objetivo, la República romana tardía articuló un sistema de arrendamiento de impuestos parecido al que rigió en las monarquías de las edades Media y Moderna. Tras calcularse un presupuesto anual estimado del monto total de los gastos, varias compañías mancomunadas arrendatarias de impuestos lo satisfacían en metálico, adquiriendo el derecho de cobro de los impuestos sobre la población en nombre del Senado romano. Son constantes las quejas de los ciudadanos ante la exacción cruel de los agentes a las órdenes de los arrendatarios de impuestos, que se cobraban con amplios beneficios lo adelantado al Estado y que exigían además intereses. En caso de no contar con la colaboración voluntaria de los contribuyentes, podían reclamar el auxilio de las legiones”. Los empadronamientos citados los realizaban los romanos para ayudar a calcular el total de los impuestos provinciales. Ese dato era esencial para luego subastar los presupuestos ante las sociedades de los publicanos.

Para el autor Karl Loewenstein; puntualiza que "los gastos ordinarios de la hacienda pública de Roma se cubrían con los ingresos propios del Estado, sin recurrir a un impuesto, signo de servidumbre. Raramente el gobierno cubría los gastos sólo con los impuestos que cobraba, así que, cuando había que realizar grandes desembolsos, Roma recurría a la guerra para sacar un sustancioso botín de los países conquistados, que se utilizaba para cubrir los gastos restantes. Aquí tenemos una de las posibles causas de la caída de Roma, ya que, cuando el Imperio pasó a estar a la defensiva, se le hizo casi 
imposible cubrir sus propios gastos, derivándose de ello una monumental crisis fiscal, monetaria, económica y, por consiguiente, política que sacudió los cimientos del estado romano, propiciando su desplome". El pago de los impuestos debía hacerse con denarios romanos, por lo tanto y puesto que se aceptaba como inevitable la soberanía de los romanos sobre la tierra, lógico era devolverles lo que ellos les habían dejado a su vez (el denario era comúnmente aceptado para todo tipo de transacciones).Respecto a las finanzas, Constantino introdujo nuevos impuestos en el sistema fiscal con el fin de equilibrar el presupuesto estatal.

Ambos autores sostienen que el principal interés económico del Estado en la antigüedad era el cobro de los impuestos para poder satisfacer sus propios gastos expresado a la sociedad de publícanos, pagaba al erario la cantidad indicada a cambio de poder cobrar los impuestos para esa provincia. El negocio, obviamente, consistía en recaudar más de lo pagado al erario. Pero a pesar de las reformas realizadas, el peso de los impuestos cada vez fue más oneroso e intolerable. Al romano, siempre le pareció excesiva la recaudación de impuestos por parte del Estado. Aunque el estado romano, obviamente, no puede compararse, en cuanto a instituciones, gasto social y desarrollo, a los modernos países de hoy en día, estos últimos y el primero tenían algo en común: necesitan dinero para cubrir los gastos. No hay persona ni cosa a la que no se le impusiera. Pero, a diferencia de lo que ocurre hoy en día, donde la mayoría de los gastos están destinados a lo que se denomina el "gasto social” Sanidad, Educación, Subvenciones, Subsidios entre otros.

Así, en nuestros días republicanos, el presupuesto público es un instrumento de gestión del Estado por medio del cual se asignan los recursos públicos sobre la base de una priorización de las necesidades de la población. Estas necesidades son satisfechas a través de la provisión de bienes y servicios públicos de calidad para la población financiados por medio del presupuesto.

El presupuesto consiste en la planificación de la actividad financiera del Estado, aprobada por ley y por un período usualmente anual. El presupuesto tiene por objeto determinar con anticipación los acontecimientos financieros que comprenden los gastos a realizar en un período dado, tendientes a satisfacer las necesidades colectivas, y los recursos que se estima recaudar para atender a dichos gastos. El Presupuesto Público es el principal instrumento de gestión del Estado para otorgar un mayor bienestar a la ciudadanía, a 
través de una asignación eficiente y eficaz de los recursos públicos, acorde con la disponibilidad de los fondos públicos.

Considerando que el presupuesto público es la herramienta principal que tiene el gobierno para obtener buenos resultados de sus intervenciones en términos calidad, costo, eficiencia, efectividad, equidad y oportunidad; el sistema presupuestario necesita una estructura fiscal coherente que lo viabilice y un esquema de gestión que potencie el uso eficiente, productivo y eficaz de los recursos públicos. Sin embargo, en el caso del Perú, existe un significativo distanciamiento entre la formulación, diseño e implementación de políticas y los resultados que se obtienen de ellas.

Desde el punto de vista del Estado, el presupuesto es uno de los instrumentos esenciales de su manejo. Es el documento financiero que balancea ingresos y gastos públicos. Asimismo, se define e instrumenta anualmente una determinada forma de vida de la sociedad, tanto en lo que se refiere a los recursos financieros que la sociedad transfiere al Estado, a través del sistema tributario, como de los bienes y servicios que la misma recibe como consecuencia de la gestión pública.

Analizando la evolución del concepto, se observa que, en el pasado el presupuesto era la expresión, en términos financieros, de lo que el gobierno pretendía llevar a cabo en un período de tiempo determinado (por regla general, un año). En su concepción moderna, el presupuesto adquirió un carácter más integral, ya que no se lo concibe sólo como la expresión financiera del programa del gobierno, sino además como una expresión más amplia y explícita del mismo.

En suma, podríamos destacar que todo Estado democrático y republicano solo puede existir si tiene un componente presupuestario pre establecido, el cual se consolida a través de los tributos, préstamos internacionales, donaciones, entre otras actividades necesariamente planificadas, pero que en su esencia nos muestra de que el presupuesto público es limitado y se sustenta en el principio de legalidad.

\section{De la clasificación del presupuesto}

\section{Del control presupuestario}

Si consideramos, que de los presupuestos públicos depende la provisión del servicio público, desarrollo de programas sociales, incluso el pago de la deuda interna y externa, su estructura merece principal resguardo por parte del Estado, por ende, de los funcionarios y servidores públicos. 
En esa medida, el control presupuestario es el proceso de descubrir qué es lo que se está haciendo, comparando los resultados con sus datos presupuestados correspondientes para verificar los logros o remediar las diferencias en los procesos de gestión pública. Para ello el Estado Peruano dentro de los alcances de la ley 28411 cuenta con el sistema nacional de presupuesto público, que regla en conjunto de principios, métodos y órganos responsables del proceso presupuestario y del gasto público.

Es así, que todo proceso presupuestario comprende programación, formulación, aprobación, ejecución y evaluación, cuyas fases deben ser operadas y resguardas en todo de acuerdo a ley en los niveles del Estado; todo ello concordante con la Ley $\mathrm{N}^{\circ} 28112$, Ley Marco de la Administración Financiera del Sector Público.

Uno de los principios fundantes de este sistema jurídico lo constituye el principio de equilibrio presupuestario “por el cual el Presupuesto del Sector Público está constituido créditos presupuestarios que representan el equilibrio entre la previsible evolución de los ingresos y los recursos a asignar de conformidad con las políticas públicas de gasto, estando prohibido incluir autorizaciones de gasto sin el financiamiento correspondiente".

\section{De la negociación colectiva}

Uno de los derechos fundamentales y respecto de los cuales es garante el Estado lo constituye el derecho del trabajo y por extensión de este el derecho Constitucional de negociación colectiva recogida en el artículo 28 de la Carta magna el cual establece "El Estado reconoce los derechos de sindicación, negociación colectiva y huelga".

Sin embargo, conforme a lo expuesto precedentemente este procedimiento de orden gubernamental depende no solo de la voluntad que gire entre los trabajadores y los representantes del Estado si no que en modo determinante dependerá de la disponibilidad de los recursos para que se puedan acordar y ejecutar los beneficios laborales que emanen en este tipo de negociación colectiva reconocido en el orden internacional.

El TC precisa que, si bien la constitución ha reconocido la negociación colectiva como un derecho fundamental de los servidores públicos, conforme se ha dicho será la ley quien perfeccione el ejercicio razonable de este derecho en el sector público, tanto en relación a su goce como a sus limitaciones y restricciones. El legislador tiene ese encargo constitucional, de afinar el diseño legal para hacer efectivo el contenido del derecho a la negociación colectiva en cada sector. El TC busca armonizar el derecho de negociación colectiva de los servidores públicos y la restricción constitucional del equilibrio 
presupuestal. En ese sentido los magistrados expresaron en sus fundamentos debidamente motivados que estas limitaciones deben de estar basados en criterios de proporcionalidad, idoneidad y necesidad pública, ya que esta se encuentra condicionada al presupuesto público nacional y de cada entidad pública descentralizada. A mayor detalle en el Expediente 00004-2020-PI/TC.

Según la Organización Internacional del Trabajo (OIT), La negociación colectiva es un mecanismo fundamental del diálogo social, a través del cual los empleadores y sus organizaciones y los sindicatos pueden convenir salarios justos y condiciones de trabajo adecuadas; además, constituye la base del mantenimiento de buenas relaciones laborales. La negociación colectiva suele ocuparse de la negociación de aspectos tales como la creación de estabilidad del empleo, el tiempo del trabajo, los incrementos salariales o las condiciones de trabajo. La ley garantizará el derecho a la negociación colectiva laboral entre los representantes de los trabajadores y empresarios, así como la fuerza vinculante de los convenios. Se reconoce el derecho de los trabajadores y empresarios a adoptar medidas de conflicto colectivo.

Fundamentalmente, la negociación colectiva se ha convertido en una fuente dinámica del Derecho Laboral por la influencia que ejerce sobre éste, la legislación del trabajo establece condiciones de trabajo y beneficios salariales que se aplican a toda la fuerza laboral, debemos considerar que éstos contemplan la posibilidad de cumplimiento por todos los empresarios, independientemente de su capacidad económica.

En efecto, el artículo $28^{\circ}$ de la Constitución dispone que "el Estado reconoce el derecho a la negociación colectiva, cautela su ejercicio democrático y fomenta la negociación colectiva, y que la convención colectiva tiene fuerza vinculante en el ámbito de lo concertado". Conforme a la Cuarta Disposición Final y Transitoria de la Constitución, las normas relativas a los derechos y libertades que aquella reconoce se interpretan de conformidad con la Declaración Universal de los Derechos Humanos y los tratados internacionales sobre la misma materia ratificados por el Perú.

En todo caso, la eficacia de los convenios colectivos no se entendía o percibía como un problema jurídico sino como un problema de índole político-sindical: su mayor o menor vinculabilidad estaba en función de las concretas relaciones de fuerza existentes entre las partes sociales en conflicto. 
Si bien es cierto el TC otorga toda las características expuestas al proceso de negociación colectiva, también es cierto de que el TC ha establecido que el aspecto presupuestario es una condición no solo importante sino determinante para dichos procedimientos, sino determinante para el desarrollo de la ejecución y validación de este tipo de negociaciones, así como en la sentencia recaída en el Expediente $\mathrm{N}^{\circ}$ 0008-2005-AI/TC, se ha señalado lo siguiente: "En el caso de las negociaciones colectivas de los servidores públicos, estas deberán efectuarse considerando el límite constitucional que impone un presupuesto equilibrado y equitativo, cuya aprobación corresponde al Congreso de la República, ya que las condiciones de empleo en la administración pública se financian con recursos de los contribuyentes y de la Nación. [...] una negociación colectiva en el ámbito laboral implica contraponer posiciones, negociar y llegar a un acuerdo real que ambas partes puedan cumplir. En tal sentido, no porque la ley disponga que todo acto relativo al empleo público que tenga incidencia presupuestaria debe estar debidamente autorizado y presupuestado se vulnera el derecho a la negociación colectiva y a la libertad sindical. En efecto, precisamente después de los acuerdos logrados mediante la negociación colectiva, conforme a la legislación vigente para los servidores públicos, los que tengan incidencia económica se podrán autorizar y programar en el presupuesto”. En suma, los límites de la negociación colectiva, según el TC, son: 1. La licitud de los acuerdos y 2. El equilibrio presupuestal.

Por otra parte, en la sentencia recaída en el Expediente $N^{\circ}$ 02566-2012-PA/TC, el supremo intérprete de nuestra Constitución ha tenido la oportunidad de pronunciarse sobre el derecho a la negociación colectiva y la prohibición de realizar cualquier tipo de aumentos al personal de la administración pública, señalando que " la mencionada previsión normativa traduce, en el ámbito legal, el principio de equilibrio presupuestario establecido en el artículo $77^{\circ}$ de la Constitución, en su condición de límite legítimo a la negociación colectiva, entre organizaciones sindicales y entidades del Estado. En ese sentido, dicha disposición normativa resulta plenamente constitucional y, por ende, vinculante para todos los poderes públicos y privados, en el marco de cualquier negociación colectiva que reúna estas características. Sin embargo, con el mismo énfasis, considera este Tribunal que, para armonizar dicho precepto normativo con el artículo $28^{\circ}$ de la Constitución, resulta preciso entender que cualquier eventual incremento y/o beneficio económico resultante de una negociación colectiva llevada a cabo con entidades 
del Estado, debe ser cubierto con recursos provenientes de ingresos propios, previamente incluidos en el presupuesto de la entidad, y de ninguna manera financiados por ingresos que tengan como origen otras fuentes [STC N ${ }^{\circ}$ 01035-2001-AC/TC, fundamentos $10 \mathrm{y}$ 11], En cualquier caso, estima este colegiado que todo incremento deberá estar previstos oportunamente en el presupuesto de la entidad al momento de la negociación, en efecto de lo cual, deberá estarlo en el presupuesto subsiguiente, a fin de no limitar irrazonablemente el principio de buena fe que debe presidir todo procedimiento de negociación colectiva".

Por otro lado, en la sentencia recaída en el Expediente 0023-2013-PI/TC establece "restricciones en relación con los incrementos salariales y la negociación colectiva, atentaría directamente contra el contenido constitucional del derecho a la negociación colectiva lo cual supone que el Estado promueva las condiciones necesarias para que las partes negocien libremente y realicen determinadas acciones positivas para asegurar las posibilidades de desarrollo y efectividad de la negociación colectiva. El Tribunal entiende que pueden imponerse restricciones de orden presupuestal a la negociación colectiva con los trabajadores del sector público y que el establecimiento de estos límites al poder de negociación colectiva puede encontrarse justificado y ser razonable atendiendo a situaciones de insuficiencia económica por las que atraviese el Estado. Sin embargo, incluso casos como el mencionado, la prohibición de negociación colectiva siempre está sujeta a criterios de temporalidad. El Tribunal juzga que las limitaciones indefinidas o que impidan que en el futuro los trabajadores puedan negociar sus condiciones laborales, más allá del periodo previsto por la ley restrictiva, son, en sí mismas, inconstitucionales”. Sin embargo, el TC fundamenta que en el derecho de información previa a la negociación colectiva: la entidad pública debe proporcionar a los trabajadores la información sobre la situación económica y social para que le permita negociar con conocimiento de causa. La información proporcionada debe estar referida al marco presupuestal. La intervención de la autoridad pública competente en la administración presupuestaria: la negociación colectiva de remuneraciones en el sector público tiene un impacto sobre el presupuesto, por lo que facilita el acuerdo de participación de la autoridad competente. Por lo general, ese rol le corresponde al Ministerio de Economía y Finanzas responsable de la elaboración del presupuesto. La negociación debe proceder con antelación la aprobación del 
presupuesto: el tiempo de la negociación colectiva debe armonizarse al procedimiento de aprobación del presupuesto.

En virtud de lo expuesto. Este Tribunal considera que las restricciones o prohibiciones a la negociación colectiva de los trabajadores del sector público que obedecen al principio de equilibrio presupuestal no pueden exceder de la vigencia anual de las leyes de presupuesto, y siempre que subsistan las razones que condujeron a adoptarlas. No obstante, se debe reiterar que durante el periodo en el que la restricción en materia de incrementos salariales está vigente, el Estado debe hacer todo lo posible por revertir la situación de crisis que ha generado tal limitación en el derecho a la negociación colectiva de los trabajadores e incluso levantar la restricción mencionada en el caso de que mejore la situación económica y financiera del Estado. Sin embargo, haciendo una interpretación se podría inferir que los servidores públicos no tendrían derecho a la negociación colectiva.

Lamentablemente en la mayoría de los procesos de negociación colectiva se hacen acuerdos indiscriminados sin tenerse en cuenta la variable presupuestaria lo cual ha dado origen a un sin número de acuerdos de negociación colectiva que a la fecha se vuelven inejecutables porque no hay presupuesto, según las estadísticas, los convenios colectivos registrados en el período 2006 - 2018 indican que el 76\% correspondió a empresas públicas $(45 \%)$ y gobiernos locales $(31 \%)$, mientras que el $24 \%$ restante se dividió entre gobiernos regionales, programas / proyectos, organismos públicos ejecutores, organismos constitucionalmente autónomos, organismos técnicos especializados, ministerios, entre otros. A mayor detalle consultado en Negociación Colectiva en el sector público 2020, Autoridad Nacional del Servicio Civil SERVIR.

Las entidades públicas con mayor incidencia de negociaciones colectivas solucionadas vía laudos arbitrales continúan siendo los organismos técnicos especializados (54\%), las universidades $(50 \%)$, gobiernos regionales $(37 \%)$, organismos constitucionalmente autónomos (19\%) y programas/proyectos (10\%).

En el período 2006 - 2018, las organizaciones sindicales y las entidades públicas han venido negociando y acordando diversas materias, siendo las más recurrentes "asignaciones y/o bonificaciones por uniforme", "asignaciones y/o bonificaciones por escolaridad", "bonificación por cierre de pliego de reclamos", “asignaciones y/o bonificaciones por refrigerio", "aumento remunerativo general al obrero", "aumento 
remunerativo general al empleado", "asignaciones o bonificaciones por el fallecimiento del trabajador".

Es importante resaltar que en el período bajo análisis se han venido acordando mejoras remunerativas vía negociación colectiva a pesar de la prohibición de la negociación de incrementos remunerativos de cualquier naturaleza en las entidades públicas, establecida en las correspondientes leyes anuales de presupuesto del sector público.

De las estadísticas expuestas un elemento distintivo de que todas ellas no se pueden ejecutar por falta de presupuesto, consecuentemente el caso de la Ley del Presupuesto Público (Pleno Jurisdiccional basado en los Expedientes Nº3-2013-PI/TC, 04-2013PI/TC y 23-2013-PI/TC (acumulados); el Tribunal Constitucional observó que las leyes de presupuesto público limitaba el derecho de los servidores públicos a participar de la negociación colectiva, específicamente, por medio de la prohibición de no poder negociar aumentos remunerativos y formular recomendaciones al Congreso de la República a que apruebe la regulación de la negociación colectiva acotada, a partir de la primera legislatura ordinaria y cuyo plazo no podría de exceder de un año, a la fecha, el Congreso no ha cumplido con legislar sobre este tema, delegando esta facultad en el Ejecutivo.

Si bien el Tribunal Constitucional está corrigiendo estas iniciativas legislativas ante los reclamos del Poder Ejecutivo, tal como tendría que ocurrir en esta ocasión, el actuar del Congreso está generando pésimos precedentes sobre la calidad de las normas que expide, creando expectativas que después de algunos meses quedan insatisfechas, a fin de que no se ejecuten ninguna negociación colectiva si es que no hay una viabilidad de disponibilidad presupuestaria.

Sobre el particular nos parece acertada dicha disposición del TC habida cuenta si bien es cierto el trabajador necesita mejorar su situación jurídica el componente del Estado entiende que el presupuesto público es único y consecuentemente no está sujeto a un capricho y a un mero reclamo sindical si

no que su asignación obedece a una planificación y programación bien estructurada conforme a los parámetros dispuestos.

\section{CONCLUSIONES}

Primero: Si bien el Estado reconoce el derecho a la negociación colectiva como expresión del derecho fundamental del trabajo este no es absoluto siendo que sus límites se encuentran entre la licitud de los acuerdos y el equilibrio presupuestal de la entidad a 
medida que los acuerdos de las comisiones paritarias no pueden afectar los demás objetivos institucionales.

Segundo: Pese a que el Tribunal Constitucional ha definido la necesidad de respetar el equilibrio presupuestal en las normas de los procesos de negociación colectiva. Lamentablemente el legislador ha hecho caso omiso a dichos aspectos mediáticos ante los reclamos del Ejecutivo dichos aspectos tienen incidencias negativas de estos procesos básicamente lo que hacen es fomentar un desequilibrio presupuestal.

\section{LISTA DE REFERENCIAS}

\section{DOCTRINA:}

AECHILE. (2014). Los impuestos en la república romana. Recuperado al 15 de diciembre de 2021: https://aechile.cl/2014/08/08/los-impuestos-en-la-republica-romana/

Law C. "Derechos Fundamentales conceptos". Recuperado al 16 de diciembre de 2021: https://fc-abogados.com/es/derechos-fundamentales-conceptos/

Rojas, Irene. (2007). Las Reformas Laborales al Modelo Normativo de Negociación Colectiva del Plan Laboral. Ius et Praxis, 13(2), 195-221. Recuperado al 20 de diciembre de 2021: https://dx.doi.org/10.4067/S0718-00122007000200009

Pasco, M. (1989). La Negociación Colectiva en el sector estatal. Repositorio institucional de la PUCP. Recuperado al 17 de diciembre de 2021: http://revistas.pucp.edu.pe/index.php/themis/article/view/10808/11306

LOEWENSTEIN, K. Roma y la Teoría General del Estado. Revista de Estudios Políticos. (1970). Recuperado al 18 de diciembre de 2021: file://Downloads/DialnetRomaYLaTeoriaGeneralDelEstado-1957299\%20(1).pdf

Autoridad Nacional del Servicio Civil - SERVIR. (2020). Negociación Colectiva en el Sector Público 2020. Recuperado al 18 de diciembre de 2021: https://cdn.www.gob.pe/uploads/document/file/1063785/Negociacion_Colectiva _2019.pdf

Bericat Guixá, B. (2021). Las causas económicas de la caída del Imperio romano. Tesis para optar el doble grado en derecho y administración y dirección de empresas. Repositorio Institucional de la UCM. Recuperado al 18 de diciembre de 2021: https://eprints.ucm.es/id/eprint/64540/

Varela, A. (2020). La negociación colectiva laboral en el sector público. Los procedimientos arbitrales económicos y su garantía al principio de equilibrio 
presupuestal. Recuperado al 16 de diciembre de 2021: https://alicia.concytec.gob.pe/vufind/Record/USMP_f19c5ca287291b3815854ef bcb5e4346

Haro Carranza, Julio Enrique (Universidad César Vallejo, 2018). Naturaleza jurídica de la negociación colectiva en la relación Estado-servidores públicos: Una propuesta a la incertidumbre en la administración pública peruana 2016 2017. Tesis par optar el grado académico de Doctor en Derecho. Recuperado al 19 de diciembre de 2021:file:///C:/Users/JENNY/Downloads/Haro_CJE\%20(5).pdf

\section{JURISPRUDENCIA:}

TRIBUNAL CONSTITUCIONAL DEL PERÚ. Expediente Nº 003-2013-PI/TC

TRIBUNAL CONSTITUCIONAL DEL PERÚ. Expediente Nº04-2013-PI/TC

TRIBUNAL CONSTITUCIONAL DEL PERÚ. Expediente Nº 0023-2013-PI/TC

TRIBUNAL CONTITUCIONAL DEL PERÚ. Expediente Nº 0025-2013-PI/TC

TRIBUNAL CONTITUCIONAL DEL PERÚ. Expediente Nº 003-2014-PI/TC

TRIBUNAL CONTITUCIONAL DEL PERÚ. Expediente Nº 008-2014-PI/TC

TRIBUNAL CONTITUCIONAL DEL PERÚ. Expediente Nº 0017-2014-PI/TC

\section{MARCO NORMATIVO:}

Constitución Política del Perú. Publicada el 10 de febrero de 2021, articulo 28. Recuperado al 15 de diciembre de 2021: https://lpderecho.pe/constitucionpolitica-peru-actualizada/

Constitución Política del Perú. Publicada el 10 de febrero de 2021, ARTÍCULO 77 Recuperado al 15 de diciembre de 2021: https://lpderecho.pe/constitucionpolitica-peru-actualizada/

Ley General del Sistema Nacional de Presupuesto. Ley No 2841. Articulo I. Recuperado al 20 de diciembre 2021: http://transparencia.mtc.gob.pe/idm_docs/normas_legales/1_0_31.pdf

Ley Marco de la Administración Financiera del Sector Público Ley Nro. 28112. $\begin{array}{llll}\text { Recuperado al de } 20 \text { diciembre } & \text { 2021: }\end{array}$ http://transparencia.mtc.gob.pe/idm_docs/normas_legales/1_0_30.pdf 